\title{
Peran Layanan Akademik Dengan Kinerja Tutor Sebagai Pemoderasi: Persepsi Mahasiswa S-1 Tuton UPBJJ Ternate
}

\author{
Muhlis Hafel ${ }^{1}$, Suriana AR Mahdi ${ }^{2}$, Mohbir Umasugi ${ }^{1}$, Hamida A. Jasin ${ }^{2}$, Anfas $^{1 *}$ \\ 1 Universitas Terbuka, Indonesia \\ 2Universitas Khairun, Indonesia \\ *Korespondensi: anfas st mm@ecampus.ut.ac.id
}

\begin{tabular}{|c|c|}
\hline & \multirow{6}{*}{ 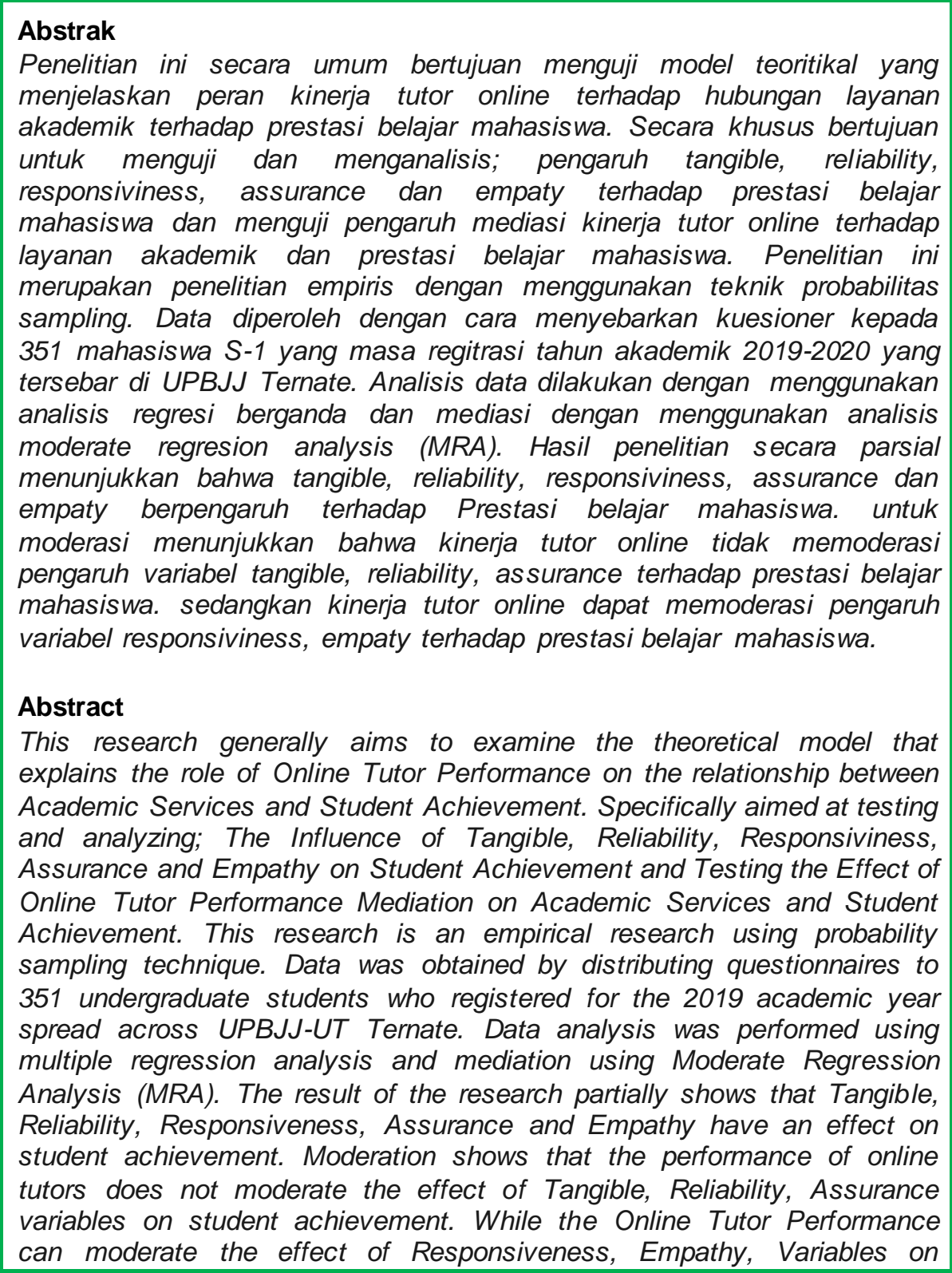 } \\
\hline & \\
\hline & \\
\hline & \\
\hline & \\
\hline & \\
\hline
\end{tabular}


Student Achievement.

\section{Pendahuluan}

Dunia pendidikan menjadi sebuah kebutuhan dasar bagi setiap manusia yang merupakan modal hidup dalam menghadapi berbagai tantangan dunia. Perkembangan dunia pendidikan semakin pesat hingga sekarang dan lembaga pendidikan diperhadapkan dengan era industri 4.0. Oleh karena itu, pendidikan tinggi harus mampu menjawab tantangan tersebut dengan menyiapkan berbagai sumber daya yang harus dimiliki agar mengarahkan civitas akademikanya bersaing secara profesional sesuai dengan bidang kompetensinya masing-masing (Caroline, 20008:1) dengan harapan setiap perguruan tinggi memiliki mahasiswa yang berprestasi di bidang akademik maupun di dunia kerja (Alam, 2016)

Perkembangan industri 4.0 tersebut memberikan dampak terhadap pola belajar yang konvensional (tatap muka) beralih ke sistem pendidikan jarak jauh, dengan memanfaatkan sumber daya komunikasi yang dilaksanakan secara online. Pada kondisi ini, Universitas Terbuka telah mengaplikasikan sistem belajar jarak jauh yang mewajibkan mahasiswa memiliki kesadaran dalam meningkatkan belajar mandirinya diluar kelas (Alam, 2016). Belajar mandiri secara efektif hanya dapat dipraktekkan jika mahasiswa mempunyai kedisiplinan, prakarsa dan motivasi yang kuat untuk belajar. Belajar mandiri tidak harus perorangan, namun juda dapat dilakukan secara berkelompok, memanfaatkan bahan ajar cetak maupun non cetak sebagai sumber pembelajaran. Karena keterpisahan tersebut maka media pembelajaran merupakan suatu kebutuhan yang sangat penting bagi pengguna (Frans dan Aisyah, 2018). Selian perpustakaan online yang disediakan oleh Universitas Terbuka dalam menunjang belajar mandiri mahasiswa, modul mata kuliah merupakan salah satu yang digunakan oleh mahasiswa Universitas Terbuka agar dapat melaksanakan belajar mandiri dengan baik. Mahasiswa diharapkan mampu secara mandiri mempelajari materi kuliah, yang mana bentuk belajar Mandiri dapat dilaksanakan baik secara invidiu, berkelompok atau dalam bentuk Tutorial Tatap Muka (TTM) maupun Tutorial Online (Tuton).

Selain itu, sistem pendidikan jarak jauh memudahkan para mahasiswa yang berstatus pekerja dalam mengatur waktu kerjanya dengan layanan kuliah jarak jauh. Holtzclaw (1986) mengemukakan bahwa bagi mahasiswa yang mengambil strata sarjana jarak jauh membutuhkan layanan akademik yang terbaik, dimana menurut Zeithalm et al, (1990) mengungkapkan bahwa terdapat lima faktor yang dapat meningkatkan kualitas layanan jasa yaitu Tangible, Reliability, Responsiviness, Assurance dan Empaty. Namun pada kenyataanya, mahasiswa Universitas Terbuka masih mengalami beberapa kendala, berupa kesukaran mencerna materi bahan ajar, merasa terasing, dan lamban mendapatkan feedback dari tutor terhadap tugas-tugas yang mereka kerjakan (Andriani, 2005). Hambatan hambatan muncul dikarenakan sebelumnya mereka sudah terbiasa belajar menggunakan sistem tatap muka melalui bimbingan seorang guru di kelas. Mereka belum terbiasa belajar menggunakan sistem belajar jarak jauh. Oleh karena itu, ketika menjadi mahasiswa yang menerapkan sistem belajar jarak jauh di Universitas Terbuka, mereka perlu mendapatkan bantuan akademik berupa layanan tutorial (Wardani, 2000). Bentuk layanan tutorial tersebut membutuhkan peran tutor yang profesional dan berkualitas. Namun hasil penelitian Frans dan 
Aisyah (2016) menunjukkan bahwa kualitas tutor rendah dilihat dari masih terdapat tutor yang; "tidak membagikan ringkasan RAT/SAT pada awal dimulainya tutorial, tidak meringkas dan menyimpulkan materi disetiap akhir pembahasan, tidak memberikan contoh soal yang akan dibahas dan tutor tidak menegur peserta yang menganggu jalannya tutorial". Oleh karena itu, perlu dilakukan penelitian untuk mengetahui apakah kinerja tutor online dapat memediasi prestasi belajar mahasiswa selama mengikuti tutorial online.

Penelitian ini mengembangkan peneltian yang dilakukan oleh Herman (2010) dengan judul penilaian peserta terhadap kinerja tutor, dan hasil tutorial dan biaya tutorial pada tutorial tatap muka di Universitas Terbuka dengan perbedaan penelitian sebagai berikut: pertama; objek penelitian Herman yakni Mahasiswa yang mengikuti tutorial tatap muka di UPBJJ Bandung, dengan jumlah sampel sebanyak 100 mahasiswa. Sedangkan objek dalam penelitian ini adalah mahasiswa yang mengikuti tutorial online di UPBJJ-UT Ternate dengan jumlah sampel sebanyak 351 Mahasiswa. Alasan menggunakan mahasiswa tuton masa registrasi 2019.2, yaitu: hampir sebagian besar mahasiswa memiliki pengetahuan yang minim terkait dengan tata cara layanan tercepat untuk memperoleh LIP registrasi dari UPBJJ-UT untuk mengaktifkan masa registrasinya dan budaya lingkungan kerja yang masih minim dalam mendukung meningkatan kompetensi sumber daya manusia. Perbedaab kedua, penelitian Herman menggunakan variabel kinerja tutor sebagai variabel dependen, sedangkan dalam penelitian ini menggunakan variabel kinerja tutor sebagai variable moderasi. Perbedaan ketiga; dalam penelitian ini, peneliti menambah variabel tangible, reliability, responsiviness, assurance dan empaty sebagai variabel independen.

Bertitik tolak dari permasalahan yang ditemukan dalam penelitian Herman di atas, maka dirumuskan masalah dalam penelitian adalah: pertama; bagaimana peran layanan akademik (tangible, reliability, responsiviness, assurance dan empaty) berpengaruh terhadap prestasi belajar mahasiswa? Kedua; bagaimana peran kinerja tutor online memoderasi layanan akademik (tangible, reliability, responsiviness, assurance dan empaty) terhadap prestasi belajar mahasiswa?

Dari penelitian ini, peneliti berupaya membangun gagasan baru mengenai konsep kinerja tutor tuton, melalui sintesis kontemplasi akademik terhadap teoriteori yang dapat menunjang. Dalam penelitian ini konsep baru yang diusulkan, yaitu pada teori kualitas dan teori layanan. Konsep ini diharapkan berperan dalam meningkatkan kualitas kerja tutor tuton maupun peningkatan prestasi belajar mahasiswa Universitas Terbuka di UPBJJ-UT Ternate.

\section{Metode Penelitian}

Jenis penelitian ini adalah penelitian kuantitatif yang menguji pengaruh tangible, reliability, responsiviness, assurance dan empaty terhadap prestasi belajar mahasiswa dan menguji pengaruh mediasi kinerja tutor online terhadap layanan akademik dan prestasi belajar mahasiswa. Penentuan jumlah sampel menggunakan metode non-probability sampling. Dimana sampel ditentukan berdasarkan beberapa pertimbangan responden yang digunakan. Kriteria yang digunakan dalam penggambilan sampel yaitu menentukan $20-25 \%$ dari total populasi yakni sebanyak 1.719 dengan jumlah sampel sebanyak 351 .

Metode pengumpulan data yaitu melalui kuesioner yang akan dijawab oleh responden. Sedangkan metode analisis data menggunakan analisis regresi linear 
berganda (multiple regression linear) yang dapat dirumuskan dengan persamaan regresi:

$\begin{aligned} Y= & \beta \alpha+\beta_{1} X_{1 a}+\beta_{2} X_{1 b}+\beta_{3} X_{1 c}+\beta_{4} X_{1 d}+\beta_{5} X_{1 e}+\beta_{6}\left[X_{1 a}-X_{5}\right]+\beta_{7}\left[X_{1 b}-X_{5}\right]+\beta_{8}\left[X_{1 c}-X_{5}\right] \\ & +\beta_{9}\left[X_{1 d}-X_{5}\right]+\beta_{10}\left[X_{1 e}-X_{5}\right]+\beta_{14}\left[X_{2}-X_{5}\right]+\beta_{n . .}+\varepsilon\end{aligned}$

Keterangan:

$\mathrm{Y}=$ Prestasi Belajar

$\alpha \quad=$ Konstanta

$\mathrm{X}_{1 \mathrm{a}}=$ Tangible

$\mathrm{X}_{1 \mathrm{~b}}=$ Reliability

$\mathrm{X}_{1 \mathrm{c}}=$ Responsiviness

$\mathrm{X}_{1 \mathrm{~d}}=$ Assurance

$\mathrm{X}_{1 \mathrm{e}}=$ Empaty

$\mathrm{X}_{3}=$ Kinerja Tutor Online

$\mathrm{X}_{1}-\mathrm{X}_{5}=$ Mediasi yang diukur dengan nilai mutlak perbedaan antara $\mathrm{X}_{\mathrm{i}}$ dan $\mathrm{X}_{4}$

$\epsilon \quad=$ eror

$\beta_{1} \beta_{2} \beta_{3} \beta_{4} \beta_{5} \beta_{6} \beta_{7} \beta_{8} \beta_{9} \beta_{n} \ldots . .=$ Koefisien Regresi

\section{Hasil Penelitian}

\subsection{Respon Rate}

Dari hasil penyebaran kuisioner di lapangan sebanyak 350 kuesioner. Kuesioner yang dikembalikan sebanyak 236 kuesioner.

Tabel 1. Respon Rate

\begin{tabular}{ccc}
\hline Keterangan & Jumlah Kuesioner & Persentase \\
\hline Jumlah kuesioner yang disebarkan & 351 & $100 \%$ \\
\hline Kuesioneryang tidak kembali & $(115)$ & $(33 \%)$ \\
\hline Kuesioner yang diisi tidak lengkap & $(0)$ & $(0 \%)$ \\
\hline Total sampel akhir pengamatan & 236 & $67 \%$ \\
\hline
\end{tabular}

Sumber: Data primer diolah, 2020

\subsection{Statistik Deskriptif}

Berdasarkan Tabel 2 menunjukkan bahwa jumlah pengamatan (N) penelitian ini yakni sebanyak 61 . Standar deviasi tiap variabel memiliki nilai yang lebih kecil dibanding dengan nilai mean. Artinya bahwa data dalam penelitian ini menyebar di sekitar rata-rata hitungnya.

Tabel 2. Statistik Deskriptif

\begin{tabular}{lccccc}
\hline \multicolumn{1}{c}{ Variabel } & $\mathrm{N}$ & Minimum & Maximum & Mean & Std. Deviation \\
\hline Tangble & 236 & 2,63 & 5,00 & 3,9754 & 0,49037 \\
\hline Reliability & 236 & 3,20 & 5,00 & 4,0305 & 0,41983 \\
\hline
\end{tabular}




\begin{tabular}{llllll}
\hline Datang & 236 & 3,00 & 5,00 & 4,0085 & 0,52484 \\
\hline Assurance & 236 & 3,00 & 5,00 & 3,9525 & 0,36172 \\
\hline Empaty & 236 & 3,00 & 5,00 & 3,9466 & 0,52644 \\
\hline MotBel & 236 & 3,33 & 5,00 & 4,0944 & 0,34634 \\
\hline
\end{tabular}

Sumber: Olah Data, 2020

Tabel 3. Hasil Ujian Hipotesis-Parsial

\begin{tabular}{lcccc}
\hline Kegerangan & Constants & $\mathrm{B}$ & $\mathrm{t}$ Tabel & Sig \\
\hline Tangible & 2,573 & 0,182 & 2,323 & 0,021 \\
\hline Reliability & 2,509 & 0,196 & 2,129 & 0,034 \\
\hline DaTang & 2,726 & 0,143 & 1,939 & 0,054 \\
\hline Assurance & 2,479 & 0,207 & 1,940 & 0,054 \\
\hline Empaty & 2,727 & 0,145 & 1,973 & 0,050 \\
\hline
\end{tabular}

Sumber: Olah Data SPSS, 2020

Tabel 4. Hasil Ujian Hipotesis-Moderasi

\begin{tabular}{lcccc}
\hline Kegerangan & Constants & $\mathrm{B}$ & $\mathrm{t}$ Tabel & Sig \\
\hline $\mathrm{X} 1 \mathrm{a}-\mathrm{X} 5$ & 3,244 & 0,074 & 1,200 & 0,231 \\
\hline $\mathrm{X} 1 \mathrm{~b}-\mathrm{X} 5$ & 3,250 & 0,069 & 1,081 & 0,281 \\
\hline $\mathrm{X} 1 \mathrm{c}-\mathrm{X} 5$ & 3,220 & 0,103 & 1,698 & $0,091^{* *}$ \\
\hline $\mathrm{X} 1 \mathrm{~d}-\mathrm{X} 5$ & 3,284 & 0,013 & 0,252 & 0,802 \\
\hline $\mathrm{X} 1 \mathrm{e}-\mathrm{X} 5$ & 3,218 & 0,116 & 1,875 & $0,062^{* *}$ \\
\hline
\end{tabular}

Adjusted Square $=0,002$

R Square $=0,006$

$\mathrm{F} 0,033$

Sig $={ }^{*} 0,05$ dan ${ }^{* *} 0,10$

Dari hasil uji statistik diperoleh persamaan regresi :

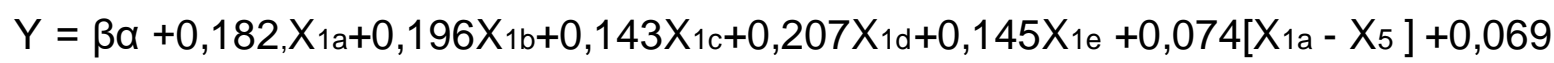
$\left[X_{1 b}-X_{5}\right]+0,103\left[X_{1 c}-X_{5}\right]+0,013\left[X_{1 d}-X_{5}\right]+0,116\left[X_{1 e}-X_{5}\right]+\beta_{n} .+\varepsilon$

Berdasarkan persamaan regresi tabel di atas maka dapat diinterpretasikan beberapa hal, antara lain:

1) Variabel Tangible mempunyai koefisien regresi yang positif yaitu sebesar 0,182 . Hal ini menunjukkan bahwa jika mengalami peningkatan Tangible sebesar 1 Persen, maka Prestasi Belajar akan ikut meningkat juga sebesar 0,182 , dengan asumsi variabel independen lainnya tetap (konstan).

2) Variabel Reliability mempunyai koefisien regresi yang positif yaitu sebesar 0,196 . Hal ini menunjukkan bahwa jika mengalami peningkatan Reliability 
sebesar 1 Persen, maka Prestasi Belajar akan ikut meningkat juga sebesar 0,196, dengan asumsi variabel independen lainnya tetap (konstan).

3) Variabel Daya Tangkap mempunyai koefisien regresi yang positif yaitu sebesar 0,143. Hasil ini memberikan gambaran bahwa jika Daya Tangkap meningkat sebesar 1 Persen, maka Prestasi Belajar akan ikut meningkat juga sebesar 0,143, dengan asumsi variabel independen lainnya tetap (konstan).

4) Variabel Assurance mempunyai koefisien regresi yang positif yaitu sebesar 0,207 . Hasil ini memberikan gambaran bahwa jika Assurance meningkat sebesar 1 Persen, maka Prestasi Belajar akan ikut meningkat juga sebesar 0,207, dengan asumsi variabel independen lainnya tetap (konstan).

5) Variabel Empaty mempunyai koefisien regresi yang positif yaitu sebesar 0,145 . Hasil ini memberikan gambaran bahwa jika Empaty meningkat sebesar 1 Persen, maka Prestasi Belajar akan ikut meningkat juga sebesar 0,145 , dengan asumsi variabel independen lainnya tetap (konstan).

6) Variabel Interaksi Tangible dan Kinerja Tutor Online memiliki koefisien regresi dengan arah positif sebesar 0,074 . Hasil ini memberikan gambaran bahwa jika variabel Interaksi Tangible dan Kinerja Tutor Online meningkat sebesar 1 persen, maka Prestasi Belajar akan ikut meningkat juga sebesar 0,074, dengan asumsi variabel independen lainnya tetap (konstan).

7) Variabel Interaksi Reliability dan Kinerja Tutor Online memiliki koefisien regresi dengan arah positif sebesar 0,069. Hasil ini memberikan gambaran bahwa jika variabel Interaksi Reliability dan Kinerja Tutor Online meningkat sebesar 1 persen, maka Prestasi Belajar akan ikut meningkat juga sebesar 0,069, dengan asumsi variabel independen lainnya tetap (konstan).

8) Variabel Interaksi Daya Tangkap dan Kinerja Tutor Online memiliki koefisien regresi dengan arah positif sebesar 0,103 . Hasil ini memberikan gambaran bahwa jika variabel Interaksi Daya Tangkap dan Kinerja Tutor Online meningkat sebesar 1 persen, maka Prestasi Belajar akan ikut meningkat juga sebesar 0,103, dengan asumsi variabel independen lainnya tetap (konstan).

9) Variabel Assurance dan Kinerja Tutor Online memiliki koefisien regresi dengan arah positif sebesar 0,013. Hasil ini memberikan gambaran bahwa jika variabel Assurance dan Kinerja Tutor Online meningkat sebesar 1 persen, maka Prestasi Belajar akan ikut meningkat juga sebesar 0,013 dengan asumsi variabel independen lainnya tetap (konstan).

10) Variabel Interaksi Empaty dan Kinerja Tutor Online memiliki koefisien regresi dengan arah positif sebesar 0,116 . Hasil ini memberikan gambaran bahwa jika variabel Interaksi Empaty dan Kinerja Tutor Online meningkat sebesar 1 persen, maka Prestasi Belajar akan ikut meningkat juga sebesar 0,116 dengan asumsi variabel independen lainnya tetap (konstan).

\subsection{Hasil Penelitian}

1) Hasil uji hipotesis pada Variabel Tangible menunjukkan nilai $P$ Value $(0,021)$ lebih kecil dari tingkat signifikansi 0,05. Hasil tersebut menujukan Bahawa 
Variabel Tangible Berpengaruh terhadap Perstasi Belajar Mahasiswa. Maka Hipoetsis 1a1 diterima.

2) Hasil uji hipotesis pada Variabel Reliability menunjukkan nilai $P$ Value $(0,034)$ lebih kecil dari tingkat signifikansi 0,05 . Hasil tersebut menujukan Bahawa Variabel Reliability Berpengaruh terhadap Perstasi Belajar Mahasiswa. Maka Hipoetsis 1 a2 diterima.

3) Hasil uji hipotesis pada Variabel Daya Tangkap menunjukkan nilai $P$ Value $(0,054)$ lebih kecil dari tingkat signifikansi 0,05 . Hasil tersebut menujukan Bahawa Variabel Daya Tangkap berpengaruh terhadap Perstasi Belajar Mahasiswa. Maka Hipoetsis 1 aз diterima.

4) Hasil uji hipotesis pada Variabel Assurance menunjukkan nilai $P$ Value $(0,054)$ lebih kecil dari tingkat signifikansi 0,05 . Hasil tersebut menujukan Bahawa Variabel Assurance berpengaruh terhadap Perstasi Belajar Mahasiswa. Maka Hipoetsis 1a4 diterima.

5) Hasil uji hipotesis pada Variabel Empaty menunjukkan nilai $P$ Value $(0,050)$ lebih kecil dari tingkat signifikansi 0,05. Hasil tersebut menujukan Bahawa Variabel Empaty berpengaruh terhadap Perstasi Belajar Mahasiswa. Maka Hipoetsis 1 a5 diterima.

6) Hasil Pengujian Hipotesis pada Interaksi Variabel Tangible dan Kinerja Tutor Online memiliki Nilai P-Vlalue sebesar 0,231 Lebih besar dari tingkat singinifikansi 0,05 . Hal ini menggambarkan bahwa Kinerja Tutor Online tidak memoderasi Pengaruh Variabel Tangible terhadap Prestasi Belajar Mahasiswa. Maka Hipotesis $\mathrm{Hb}$ d ditolak.

7) Hasil Pengujian Hipotesis pada Interaksi Variabel Reliability dan Kinerja Tutor Online memiliki Nilai P-Vlalue sebesar 0,281 Lebih besar dari tingkat singinifikansi 0,05 . Hal ini menggambarkan bahwa Kinerja Tutor Online tidak memoderasi Pengaruh Variabel Reliability terhadap Prestasi Belajar Mahasiswa. Maka Hipotesis Hb2 ditolak.

8) Hasil Pengujian Hipotesis pada Interaksi Variabel Daya Tangkap dan Kinerja Tutor Online memiliki Nilai P-Vlalue sebesar 0,091 Lebih Kecil dari tingkat singinifikansi 0,10 . Hal ini menggambarkan bahwa Kinerja Tutor Online dapat memoderasi Pengaruh Variabel Daya tangkap terhadap Prestasi Belajar Mahasiswa. Maka Hipotesis Hb3 dterima.

9) Hasil Pengujian Hipotesis pada Interaksi Variabel Assurance dan Kinerja Tutor Online memiliki Nilai P-Vlalue sebesar 0,802 Lebih Besar dari tingkat singinifikansi 0,10 . Hal ini menggambarkan bahwa Kinerja Tutor Online tidak memoderasi Pengaruh Variabel Assurance terhadap Prestasi Belajar Mahasiswa. Maka Hipotesis $\mathrm{Hb}_{4}$ ditolak.

10)Hasil Pengujian Hipotesis pada Interaksi Variabel Empaty dan Kinerja Tutor Online memiliki Nilai P-Vlalue sebesar 0,062 Lebih Kecil dari tingkat singinifikansi 0,10. Hal ini Empaty terhadap Prestasi Belajar Mahasiswa. Maka Hipotesis Hb5 diterima. 


\section{Pembahasan}

\section{Tangible Berpengaruh terhadap Perstasi Belajar Mahasiswa}

Hasil pengujian hipoetsis penunjukan bahwa, tangible berpengaruh terh adap prestasi belajar mahasiswa, maka hipotesis 1a1 ditolak. Hasil penelitian ini menunjukkan bahwa bentuk bukti langsung, seperti penampilan fisik dan perlengkapan yang berupa kebersihan, kerapian dan kenyamanan ruangan. Penataan ruang kelas maupun kesiapan dan kebersihan alat-alat yang dipakai untuk belajar dapat berpengaruh terhadap prestasi belajar mahasiswa. Hasil penelitian ini sejalan dengan data deskriptif yang menunjukkan bahwa rata rata mahasiswa menjawab dengan setuju bahwa fasilitas tutorial online (Website), buku materi pokok, kemudahan dalam mengakses toko buku online (TBO) dan akses naskah serta fasilitas ujian akhir sangat mempengaruhi prestasi belajar mahasiswa.

Hasil penelitian ini sejalan dengan hasil penelitian Susanto (2014) yang menunjukkan bahwa tangible dapat berpengaruh terhadap kepuasan mah asiswa. Demikian juga dengan penelitiannya Zulganef (2002) dan Samosir (2005) menunjukkan bahwa tangible merupakan dimensi kualitas layanan yang dapat meningkatkan kepuasan mahasiswa.

\section{Reliability Berpengaruh terhadap Perstasi Belajar Mahasiswa}

Hasil penelitian menunjukkan bahwa relibility berpengaruh terhadap prestasi belajar mahasiswa. Hasil deskriptif menunjukkan bahwa pada umumnya mahasiswa setuju pelayanan mahasiswa dapat dihandalkan, bentuk pelayanan tersebut berupa; layanan pra registrasi, kemudahan akses informasi terkait dengan LIP, buku materi pokok dapat diterima sebelum proses pembelajaran dimulai, dan layanan pelaksanaan tutorial maupun ujian akhir dilaksanakan secara baik. Hasil penelitian ini sejalan dengan penelitian Samosir (2005) yang menunjukkan bahwa relaibility berpengaruh terhadap kepuasan mahasiswa.

\section{Responsiviness Berpengaruh terhadap Perstasi Belajar Mahasiswa}

Hasil peneltiian menunjukkan bahwa daya tangkap berpengaruh terhadap prestasi belajar mahasiswa. Hasil ini sesuai dengan hasil deskripsi yang menunjukkan bahwa setiap kebutuhan mahasiswa yang terkait dengan kebutuhan administrasi, layanan tutorial, tutor cepat tanggap dalam memberikan solusi kepada mahasiswa. Hasil penelitian ini sejalan dengan penelitiannya Samosir (2005) yang menunjukkan bahwa daya tangkap berpengaruh terhadap kepuasan mahasiswa.

\section{Assurance Berpengaruh terhadap Perstasi Belajar Mahasiswa}

Hasil penelitian menunjukkan bahwa assurances berpengaruh terhadap prestasi belajar mahasiswa. Hasil ini diperkuat dengan hasil deskripsi yang menunjukkan bahwa rata rata mahasiswa setuju terhadap bentuk layanan akademik dari pihak pegawai maupun tutor dan dapat dipercaya. Pegawai dan tutor dapat mengupdate informasi terbaru kepada mahasiswa dan mahasiswa 
mudah memperoleh informasi tentang kegiatan akademik. Hasil Penelitian inipun sejalan dengan penelitian Samosir (2005) yang menunjukkan bahwa assurances berpengaruh terhadap kepuasan mahasiswa.

\section{Empaty Berpengaruh terhadap Perstasi Belajar Mahasiswa}

Hasil penelitian menunjukkan bahwa empaty yang diberikan tutor berpengaru $\mathrm{h}$ terhadap prestasi belajar mahasiswa. Hasil ini diperkuat dengan hasil deskripsi yang menunjukkan bahwa dalam bentuk layanan akademik, tutor tidak membeda-bedakan antara mahasiswa yang satu dengan mahasiswa yang lainnya. Tutor memiliki insiatif dalam memberikan informasi terbaru kepada mahasiswa dan tutor tanggap terhadap persoalan yang ditanyakan oleh mahasiswa. Hasil penelitian ini sejalan dengan penelitian Samosir (2005), menunjukkanbahwa empaty berpengaruh terhadap kepuasan mahasiswa.

\section{Kinerja Tutor Memoderasi Tangible, Reliability, Daya Tangkap, Assurance, Empaty, Terhadap Perstasi Belajar Mahasiswa}

Hasil pengujian hipotesis pada variabel moderasi menunjukkan, kinerja tutor tidak terbukti memoderasi pengaruh tangible, reliability, assurance, terhadap prestasi belajar mahasiswa, namun kinerja tutor terbukti memoderasi pengaruh daya tangkap terhadap prestasi belajar mahasiswa. Hal ini menunjukkan bahwa kinerja tutor dapat memperkuat pengaruh daya tangkap, empaty dan lingkungan kerja terhadap prestasi belajar mahasiswa.

\section{Kesimpulan}

Dari hasil pembahasan, dapat disimpulkan bahwa: tangible, reliability, daya tangkap, assurance dan empaty, berpengaruh terhadap prestasi belajar mahasiswa. Kinerja tutor online tidak memoderasi pengaruh tangible, reliability, assurance terhadap prestasi belajar mahasiswa. Namun kinerja tutor dapat memoderasi pengaruh daya tangkap dan empaty terhadap prestasi belajar mahasiswa.

Untuk itu, dalam pelaksanaan tuton, empaty dan kemampuan daya tangkap tutor menjadi penting ditingkatkan. Apalagi dalam pelaksanaan tuton, tutor dan mahasiswa tidak bertatap muka langsung, maka disini daya tangkap tutor penting untuk melihat lebih jelih, sejauhmana mahasiswa puas dengan layanan tutorial yang diberikan. Setiap ada kendala yang dihadapi mahasiswa, empaty dari tutor harus ada dan segera tanggap, memberikan solusi agar mahasiswa dapat mengikuti tuton dengan baik dan lancar. Dengan adanya empaty dan daya tangkap dari tutor, maka akan meningkatkan prestasi belajar mahasiswa.

\section{Referensi}

Alam, A. M. (2016). Pengaruh Motivasi Belajar Dan Metode Pembelajaran Terhadap Prestasi Belajar Mahasiswa Program Studi Komputerisasi Akuntasi. Bijak-Majalah IImiah IImu Administrasi, Volume XII(No. 02).

Andriani, D. (2005). Mahasiswa S2 pada Sistem Pendidikan Jarak Jauh: Pemanfaatan Internet dan Bantuan Belajar. Jurnal Pendidikan Terbuka Dan Jarak Jauh, 6(2), 77-91. http://www.Ippm.ut.ac.id/ptj/PTJJ Vol 6.2 september 


\section{5/ptj62durri.pdf}

Caroline, M. (2008). Motivasi Mengikuti Perkuliahan pada Mahasiswa Fakultas Psikologi Universitas Katolik Soegijapranata Semarang Ditinjau dari Persepsi terhadap Kinerja Mengajar Dosen.

Frans, Y. A., \& Aisyah, S. (2018). Effect of the quality of online tutorial services on the satisfaction and loyalty of students FISIP - "University X ". Jurnal Pendidikan Terbuka Dan Jarak Jauh, 19(1), 1-12.

Herman. (2010). Penilaian Peserta Terhadap Kinerja Tutor, dan Hasil Tutorial dan Biaya Tutorial Pada Tutorial Tatap Muka Di Universitas Terbuka. Jurnal Pendidikan Terbuka Dan Jarak Jauh, 11(2), 84-98.

Holtzclaw, L. R. (1986). Human development and the distance learner. I.C.D.E Bulletin, 10, $17-19$.

Samosir, Z. Z. (2005). Pengaruh Kualitas Pelayanan Terhadap Kepuasan Mahasiswa Menggunakan Perpustakaan USU. Jurnal Studi Perpustakaan Dan Informasi, 1(1), 28-36.

Susanto, H. (2014). Pengaruh layanan akademik terhadap kepuasan mahasiswa Program pascasarjana Universitas Terbuka Pada unit program belajar jarak jauh (UPBJJ) Mataram. Jurnal Pendidikan Terbuka Dan Jarak Jauh, 15(2), 198.

Wardani, I. (2000). Program Tutorial Dalam Sistem Pendidikan Tinggi terbuka dan Jarak Jauh,. Jurnal Pendidikan Tinggi Jarak Jauh, 1(2), 41-52.

Zeithalm, P. dan B. (1990). Delivering Quality Service: Balancing Customer Perceptions and Expectations.

Zulganef. (2007). Hubungan Antara Sikap Terhadap Bukti Fisik, Proses, dan Karyawan Dengan Kualitas Keterhubungan, Serta Perannya Dalam Menimbulkan Niat Ulang Membeli dan Loyalitas. Jurnal Riset Dan Manajemen, 2(3), 98 - 115. 